\title{
George Washington Crile, anoci-association, and pre-emptive analgesia
}

\author{
Joel Katz \\ Department of Psychology, The Toronto Hospital, Toronto General Division, Toronto, Ont. M5G 2C4 (Canada)
}

The newly emerging field of pre-emptive analgesia (Woolf 1991) has developed directly from basic science research carried out over the past decade. In particular, studies by Woolf and Wall (1986), Dickenson and Sullivan (1987), and Coderre et al. (1990) demonstrated that administration of opioids or local anesthetics before noxious stimulation prevented development of injury-induced spinal hyperexcitability and pain-related behaviours. By contrast, the same treatments are significantly less effective when administered only minutes later, after the prolonged central excitability or pain behaviours have been established. The editorial in $P A I N$ by Wall (1988) and the accompanying paper by McQuay et al. (1988) provided the impetus for the first controlled study of pre-emptive analgesia in patients scheduled for surgery. Postoperative pain intensity was lower if patients received spinal local anesthesia or general anesthesia plus local anesthetic infiltrations into the surgical field prior to surgical incision compared with general anesthesia alone (Tverskoy et al. 1990). Since that time, others have demonstrated that pre-incisional administration of different classes of analgesic agents results in less post-operative pain and reduced analgesic consumption when compared with non-treated control patients (see McQuay 1992 and Coderre et al. in press, for reviews). More recently, pre-incisional epidural administration of an opioid (Katz et al. 1992) and pre-incisional local anesthetic infiltrations (Ejlersen et al. 1992) have been shown to be more effective in reducing postoperative pain and/or analgesic requirements than postincisional (Katz et al. 1992) or post-surgical (Ejlersen et al. 1992) administration of the same agent by the same route. This orderly progression from basic science research to clinical outcome studies is in large part a reflection of the co-operation and inter-disciplinary interest within the international community of scientists and clinicians involved in pain research.

As outlined above, the current interest in pre-emptive analgesia stems from recent basic science studies carried out over the past 10 years. However, more than
75 years ago, George Washington Crile (1864-1943) developed a theory of anoci-association in which he raised the possibility that pain after surgery may be amplified if the CNS received impulses at the time of surgery (Crile 1913). Crile was a prolific author of 24 books and more than 400 articles (English 1980). A surgeon in the late 19th and early 20th centuries, Crile pioneered the study of surgical shock at a time when radical surgery was a dominant force in North America. He combined laboratory investigations of shock and exhaustion with astute clinical observation to improve the safety of surgical procedures for his patients. His research spanned many fields and in developing his various theories he incorporated research findings and concepts from anesthesiology, biology, physiology, psychology, and surgery.

The idea of anoci-association developed out of Crile's studies of shock and exhaustion (see Fig. 1). Crile (1913) believed that both intense fear and noxious stimulation produced shock. Moreover, he assumed that the effects of shock on the CNS were identical whether brought about by distressing emotional events or noxious somatic stimuli. He proposed that shock and exhaustion could be prevented, and the patient's postoperative status improved, by blocking all noxious or harmful (anoci) stimuli (associations) from reaching the brain during the surgical operation. Accordingly, Crile recommended general anesthesia to prevent traumatic emotional experiences from reaching conscious awareness and pre-incisional plus intra-operative local anesthetic infiltrations to prevent noxious surgical inputs from reaching the brain. Together, the administration of these agents provided for what Crile termed the shockless operation through anoci-association.

In order to achieve complete anoci-association, Crile advocated the administration of multiple anesthetic agents and techniques, before, during and after surgery, heralding the current trends in pre-emptive analgesia (Woolf 1991) and multi-modal, balanced analgesia (Dahl et al. 1992; Dahl et al. 1990). In discussing the 


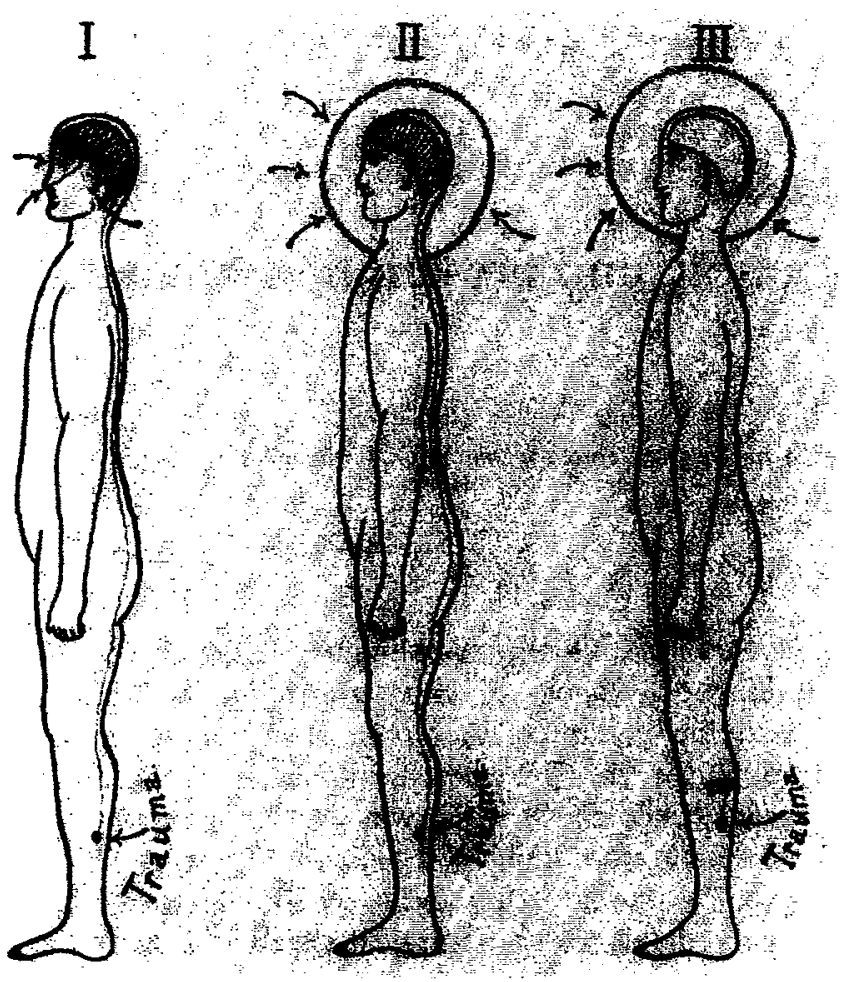

Fig. 1. Illustration of Crile's concept of anoci-association. I: in the conscious patient, auditory, olfactory, and visual input from special sense organs, and noxious somatic impulses from peripheral nociceptors are transmitted to the brain where they contribute to shock and exhaustion. II: under general anesthesia alone, noxious somatic impulses arising from trauma continue to reach the brain. III: the shockless operation achieved by complete anoci-association. Transmission of noxious auditory, olfactory, and visual impulses are prevented from reaching the brain with use of general anesthesia and noxious somatic impulses arising from the trauma are blocked by local anesthesia (reproduced from Crile and Lower 1914).

importance of complete blockade, Crile wrote "there is no single agent that alone can produce anoci-association, which is the goal of operative surgery. We, therefore, do not advocate ether alone, nor chloroform alone, nor nitrous-oxid-oxygen alone; we do not advocate local anesthesia alone, nor morphin and scopolamin alone, nor spinal anesthesia alone, but through selection and combination of anesthetics we aim to attain the anesthesia that in the case in hand will exclude all stimuli from the brain, and thereby attain anoci-association" (Crile and Lower 1914, p. 109).

Crile's technique for ensuring complete anoci-association included pre-medication with morphine plus scopolamine, general anesthesia with $\mathrm{N}_{2} \mathrm{O} / \mathrm{O}_{2}$ (plus ether if required), intra-operative morphine (if required), routine use of intradermal and subcutaneous infiltrations of a local anesthetic before skin incision, successive infiltrations of fascia, muscle, and other tissues before division, and postoperative injection of quinine and urea hydrochloride to protect the patient from nociceptive impulses arising from the wound.
Crile reported a marked reduction in morbidity and mortality using anoci-association. In 1908, the year before anoci-association was introduced where he worked at Lakeside Hospital in Cleveland, Ohio, the mortality rate for all operations was $4.4 \%$. By 1913 , it had dropped to $1.8 \%$ (Crile and Lower 1914).

Although anoci-association was developed to prevent surgical shock, Crile did refer specifically to the benefits of anoci-association on acute postoperative pain. Moreover, there is even an indication that he believed the analgesic effect associated with anoci-association would long outlast the clinical duration of action of the analgesic agents used pre-operatively (Crile 1913) - a crucial feature of pre-emptive analgesia. In an address delivered at the Massachusetts General Hospital on the 64th anniversary of Ether Day in 1910 , Crile (1910) discussed the role of summation of repetitive noxious inputs in producing hyperalgesia, and although the example he describes involved peripheral sensitization of nociceptors, the concept of summation clearly implied a central mechansim. What is most remarkable, however, is that Crile attributed the problem of painful scars to a change in central neural function and that he ascribed allodynia-like symptoms to a lowered threshold of neurons in the brain.

"The lesion which produces a painful scar is in the brain, not at the site of the wound. It is explained by a fundamental principle of nerve conduction; that is, a strong traumatic or psychic stimulus produces some change in conductivity somewhere in its cerebral arc, the effect of which is to lower the threshold of that arc.... After the stimulus of physical trauma,... the arc... suffers a lowered threshold and hence from that time on mere trifles become adequate stimuli. Now if an operation be so performed that no strong stimulus reaches the brain, either during or after the operation, then the threshold of the cerebral arc from the wound will not be lowered. Since the threshold is not lowered, contact with the scar or any injury to that part will have little more effect than will contact with any other part of the body. Hence we see how painful scars may be minimized or prevented by complete anociassociation" (Crile and Lower 1914, pp. 215 216).

\section{References}

Coderre, T.J., Vaccarino, A.L. and Melzack, R., Central nervous system plasticity in the tonic pain response to subcutaneous formalin injection, Brain Res., 535 (1990) 155-158.

Coderre, T.J., Katz, J., Vaccarino, A.L. and Melzack, R., Contribution of central neuroplasticity to pathological pain: review of clinical and experimental evidence, Pain, 52 (1993) 259-285.

Crile, G.W., Phylogenetic association in relation to certain medical problems, Boston Med. Surg. J., 163 (1910) 893-904. 
Crile, G.W., The kinetic theory of shock and its prevention through anoci-association (shockless operation), Lancet, 185 (1913) 7-16.

Crile, G.W, and Lower, W.E., Anoci-association, W.B. Saunders, Philadelphia, PA, 1914.

Dahl, J.B., Rosenberg, J., Dirkes, W.E., Mogensen, T. and Kehlet, H., Prevention of postoperative pain by balanced analgesia, $\mathrm{Br}$. J. Anaesth., 64 (1990) 518-520.

Dahl, J.B., Hansen, B.L., Hjortsø, N.C., Erichsen, C.J., Møiniche, S. and Kehlet, $H$., Influence of timing on the effect of continuous extradural analgesia with bupivacaine and morphine after major abdominal surgery, Br. J. Anaesth., 69 (1992) 4-8.

Dickenson, A.H. and Sullivan, A.F., Subcutaneous formalin-induced activity of dorsal horn neurones in the rat: differential response to an intrathecal opiate administered pre- or post-formalin, Pain, 30 (1987) 349-360.

Ejlersen, E., Bryde Anderson, H., Eliasen, K. and Mogensen, T., A comparison between preincisional and postincisional lidocaine infiltration and postoperative pain, Anesth. Analg., 74 (1992) 495-498.

English, P.C., Shock, Physiological Surgery, and George Washington Crile: Medical Innovation in the Progressive Era, Greenwood Press, Westport, CT, 1980.
Katz, J., Kavanagh, B.P., Sandler, A.N., Nierenberg, H., Boylan, J.F., Friedlander, M. and Shaw, B.F., Preemptive analgesia: clinical evidence of neuroplasticity contributing to postoperative pain, Anesthesiology, 77 (1992) 439-446.

McQuay, H.J., Pre-emptive analgesia, Br. J. Anaesth., 69 (1992) 1-3.

McQuay, H.J., Carroll, D. and Moore, R.A., Post-operative orthopaedic pain - the effect of opiate premedication and local anaesthetic blocks, Pain, 33 (1988) 291-295.

Tverskoy, M., Cozacov, C., Ayache, M., Bradley, E.L. and Kissin, I., Postoperative pain after inguinal herniorraphy with different types of anesthesia, Anesth. Analg., 70 (1990) 29-35.

Wall, P.D., The prevention of post-operative pain, Pain, 33 (1988) 289-290.

Woolf, C.J., Central mechanisms of acute pain. In: M.R. Bond, J.E. Charlton and C.J. Woolf (Eds.), Proc. of the VIth World Congress on Pain, Elsevier, Amsterdam, 1991, pp. 25-34.

Woolf, C.J. and Wall, P.D., Morphine-sensitive and morphine-insensitive actions of $\mathrm{C}$-fibre input on the rat spinal cord, Neurosci. Lett., 64 (1986) 221-225. 